\title{
Assessment of an Enhanced Thin Film Model to Capture Wetting and Drying Behavior in an Aero-Engine Bearing Chamber
}

\author{
Kuldeep Singh ${ }^{1}$, Medhat Sharabi ${ }^{1}$, Stephen Ambrose ${ }^{1}$, Carol Eastwick ${ }^{1}$, Richard Jefferson-Loveday ${ }^{1 *}$, Jing Cao $^{2}$, \\ Adrian Jacobs ${ }^{3}$ \\ ${ }^{1}$ University Technology Centre in Gas Turbine Transmission Systems, Faculty of Engineering, the University of \\ Nottingham, Nottingham, NG7 2RD, UK \\ ${ }^{2}$ ANSYS Inc., 6 Europa View, Sheffield S9 1XH, UK \\ ${ }^{3}$ Rolls-Royce plc. PO Box 31, Derby, DE24 8BJ
}

\section{ABSTRACT}

In the present work, a wetting and drying model is coupled with Eulerian Thin-Film model (ETFM) to analyze the wetting and drying behavior inside the bearing chamber. In the enhanced model, an additional source term is included to account for the contact angle effect. These models were coupled with volumeof-fluid (VOF) such that the core region is resolved by VOF and region close to the chamber walls, where a thin film is expected is resolved by either ETFM or enhanced ETFM model. Numerical studies are conducted for a shaft speed of 5,000 rpm, lubricant and air flow rates of $100 \mathrm{l} / \mathrm{hr}$ and $10 \mathrm{~g} / \mathrm{s}$ respectively, at a scavenging ratio of 4 . In the case of enhanced ETFM model lubricant to surface contact angle was varied from $10^{\circ}$ to $45^{\circ}$. The performance of enhanced ETFM model is evaluated to capture drying and wetting behavior on a flat plate and found to be satisfactory. Film thickness prediction of enhanced ETFM model is found to be comparable with the VOF predictions reported in the literature. The effect of contact angle on the spreading of oil and film thickness is found to be small for the investigated conditions on an aero-engine bearing chamber.

\section{NOMENCLATURE Acronyms \\ CA Contact Angle \\ ETFM Eulerian Thin film Model \\ HPC High Performance Computing \\ SR Scavenge Ratio \\ SST Shear Stress Transport \\ TD Turbulence Damping \\ UDF User-Defined Function \\ VOF Volume of Fluid}

*Address all correspondence to this author. The author's current contact information:richard.jefferson-loveday@nottingham.ac.uk

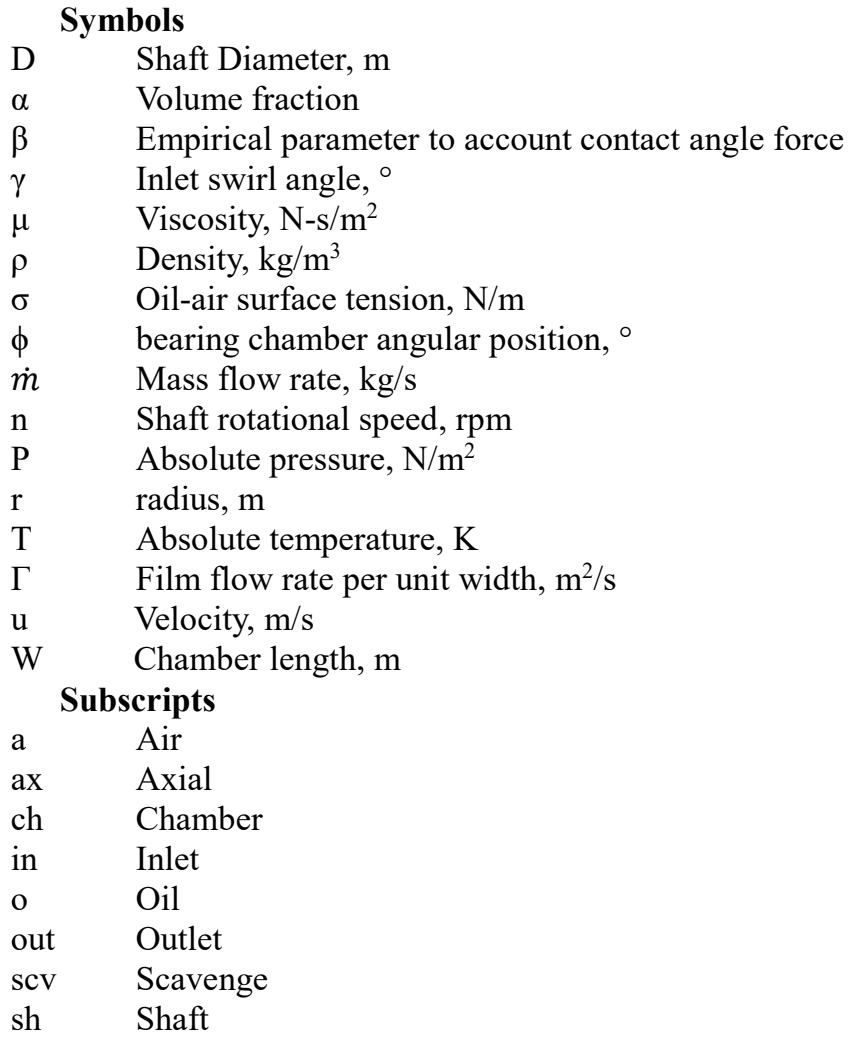

\section{INTRODUCTION}

The main function of aero-engine bearing chambers is to collect the lubricant dispersed from the bearings and to send it to the sump for reuse. A very complex two-phase flow feature is observed inside the bearing chamber because of the interaction of the lubricant with the air driven by the rotating shaft. Depending on the shaft speed, Kurz et al. [1] identified two distinct flow regimes inside the bearing chamber. The first flow regime corresponds to the lower shaft speeds; in this regime, lubricant flow is mainly driven by gravity and dry regions on the bearing chamber wall occur. The second flow regime appears at 
higher shaft speeds; the oil film in this regime is more homogeneous and rotating as compared with the first regime, although dry regions can occur in the wake of geometric features, Eastwick et al. [2]. These flow regimes are depicted in Fig. 1.

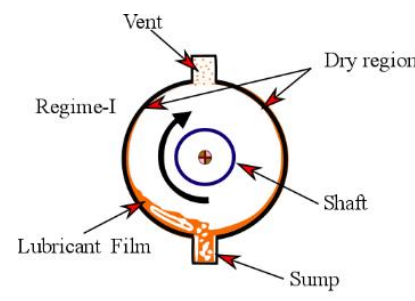

(a)

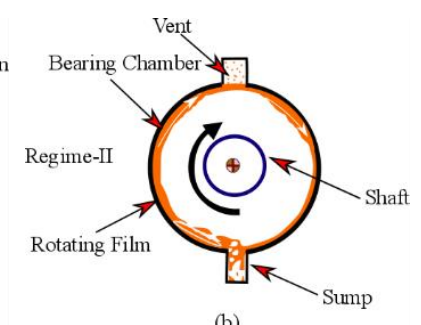

(b)
Fig. 1 Schematic diagram showing two distinct flow regimes in bearing chamber.

Dry regions are disadvantageous for heat transfer. The operating temperature of the modern gas turbines used for aeroengines is greater than $1500^{\circ} \mathrm{C}[3,4]$. Due to heavy thermal loading; shafts, bearings and bearing chambers are also exposed to very high temperature. The lubricating oil which serves the purpose of lubrication as well as cooling, extracts heat to ensure smooth operation. But, the operating temperature for the jet engine lubricating oil is limited to $200^{\circ} \mathrm{C}$ [5]. Beyond this temperature, thermal degradation such as coking and premature ageing of lubricating oil are observed. Identifications of dry regions can be helpful to avoid these problems. Iso and Chen [6] investigated wetting characteristics of gravity driven film flow on an inclined flat plate using volume of fluid (VOF). The effect of flow rate and surface texture on the flow transition from film flow (fully wetted) to rivulet flow (partially wetted) was studied. This study revealed that the transition from film flow to rivulets flow depends primarily on the history of the change of interfacial surface shape. Surface texture was also found to affect the wetting characteristics. Surface wettability was higher for the wavy textured surface as compared to the plain surface. A comparison of numerical results obtained from VOF with the experimental and theoretical results showed that VOF method was capable to predict flow transition.

Singh et al. [7] used VOF method to investigate gravity driven film flow on an inclined flat plate to study the effect of inlet size, inclination angle, contact angle, flow rate and solvent properties. Interfacial area and film thickness was evaluated in this study and Kapitza number $(\mathrm{Ka})$ was proposed as a parameter to scale the results. The contact angle was found to have negligible effect on a fully wetted plate. However, in the case of partial wetting, contact angle was a key parameter that dictated the wetting dynamics. In a successive study, Singh et al. [8] investigated breakup of rivulets falling on an inclined plate using VOF method. They proposed a relation in terms of Weber number as a function of Kapitza number to distinguish stable rivulet and unstable rivulet. Bonart et al. [9] conducted experimental study to investigate the effect of surface tension, viscosity, inclination angle, and mass flow on the interfacial area of rivulets. They proposed a correlation for interfacial area based on Reynolds and Kapitza numbers.

In the case of the bearing chamber, gravity and shear forces drive lubricating film. Veron and Melville [10] experimentally studied stability and transition of wind-driven water surfaces and reported that the waves generated on the water surface are strongly affected by the wind shear. With increase in the wind speed, instabilities were found to grow. These instabilities disrupted the momentum and thermal boundary layer and leads to an increased heat transfer. Experimental and numerical study of Marati et al. [11] also highlighted enhancement in heat transfer with increase in gas side Reynolds number. Volume of fluid method was used in the numerical study of Marati et al. [11] and a reasonable agreement with the experimental results was reported. Lan et al. [12] conducted an experimental and numerical study to investigate the effect of air velocity, liquid flow rate, surface tension coefficient and wall contact angle on the film thickness and width in a duct. The spread of liquid film and its thickness was measured using an interferometric technique. Volume of fluid (VOF) model was used in the numerical study. They reported that the film thickness decreases with the increase in air velocity, while film thickness and width increases at higher flow rate of liquid. This study also revealed that film width decreases with increase in either surface tension coefficient or wall contact angle without affecting film thickness significantly. Comparison of numerical results with the experimental results indicated that the use of dynamic contact angle in numerical simulations gives close results to the experimental observation as compared to the static contact angle. Moreover, dynamic contact angle was assigned arbitrarily in their numerical study.

Leng et al. [13] experimentally studied wind-driven film flows on a horizontal flat plate. The effect of wind speed on instantaneous film thickness and on the structure of the wave film was reported. A correlation for interfacial shear factor was proposed to get mean film thickness. Leng et al. [14] investigated gravity and shear driven film flow on a flat plate. Plate inclination angle was varied from $0^{\circ}$ (shear driven) to $\pm 45^{\circ}$ to account effect of gravity force. The direction of shear force and gravity force was same for +ve angle of inclination and opposite for -ve angle of inclination. They reported that gravitational forces has an impact on superficial waves at lower air speed. But, in the case of high air shear, gravity had a weak influence on interfacial shape. All of these studies indicates that the surface shear force alters the film flow dynamics and require appropriate treatment for the applications like bearing chambers.

A numerical study of Hirt and Nichols [15] showed that the standard volume of fluid (VOF) method is not capable to account for high shear at the interface. Tkaczyk and Morvan [16] reported that VOF combined with Level Set (LS) technique gives a better approximation of the interface curvature and surface tension forces. Researchers such as Krug et al. [17], Bristot et al. [18] investigated VOF method for the bearing chamber applications. A significant deviation in the numerical results as compared to the experimental results was reported. Krug et al. [17] also highlighted the shortcoming of VOF method when it 
was applied for the calculation of shear driven liquid wall films with two equations turbulence model for the bearing chamber application. Moreover, VOF approach requires very fine grids, typically one order smaller than the film-thickness[19] which results in very high computational cost for the industrial thinfilm flows.

Kakimpa et al. [19] proposed a coupled ETFM and VOF approach to predict the film thickness over bearing chamber wall. In the coupled approach, oil film is resolved by ETFM in the region that are otherwise computationally expensive for VOF and core flow region is resolved by VOF. Film thickness in the bearing chamber is very small as compared to the other dimensions of the chamber and hence the use of ETFM approach is justified. In the case of ETFM film thickness in not resolved explicitly using a computational grid, rather three-dimensional Navier-Stokes equations are depth-averaged across the film thickness. Depth averaging gives a set of two dimensional thinfilm equations. Thus, the computational cost is reduce. Ashmore et al. [20], Kay et al. [21] and Kakimpa et al. [22,23] used this approach for predicting rimming flow. In the case of rimming flows, three steady flow regimes are identified viz. smooth, shock, and pool, Kakimpa et al. [22]. These regimes are mainly dependent on the balance between viscous, gravitational and interfacial shear stresses. Smooth solution is obtained when surface shear force are sufficient to overcome the gravitational force. This condition is analogous to regime-II in the bearing chamber reported by Kurz et al. [1]. Pool flow condition is observed when gravitational forces dominates over the shear force, similar to the flow regime-I in bearing chamber. Shock flow condition represent a transition between these two conditions. Wang et al. [24] used ETFM approach for the bearing chamber applications. In this study, the core air flow information was extracted from a precursor simulation of the airflow between shaft and chamber. The oil film distribution was computed assuming weak convection. This study revealed that shear stresses computed from air only simulation, ignoring oil film, were not equivalent to air shear stresses on film.

Martin et al. [25] implemented Eulerian thin film model in open-source CFD code, OpenFOAM to investigate gravitydriven thin film flow. The developed model was found to predict time-averaged film thickness and fluid speed profiles with good accuracy whereas wave formation and wave speed was predicted with reasonable accuracy. Meredith et al. [26] investigated experimentally and numerically partially wetting on a flat surface due to gravity driven falling liquid film. Film distribution and the wet area fraction was obtained from the images of infrared thermography. In the numerical simulations, Eulerian thin film model (ETFM) was used. This mathematical model was implemented in OpenFOAM. Numerical results revealed that the model could predict the transition from film flow to rivulets if inlet film mass flow rate is altered in the simulations. These studies showed the potential of thin film model to predict film flow and rivulet formation. In the study of Meredith et al. [26] contact angle forces were also included in the mathematical model. The contact angle was assumed to be static. This assumption enabled the use of Young's law to calculate static contact angle. Although, contact line model has inherent limitation. It is because; a non-integrable singularity occurs in the stress term at the contact line where solid, liquid and gas phases interacts. This signifies an unphysical and infinite force [27]. Consequently, continuum hypothesis fails in the region close to the contact line. In order to avoid this, use of Navier slip boundary condition on solid surface is one of the accepted solution [28]. When capillary forces are significant, a boundary condition is specified in terms of the contact angle at the contact line $[29,30]$. This can be done either by specifying static contact angle and slip boundary condition at interface or specifying dynamic contact angle. Moreover, the calculation of dynamic contact angle is much more complex.

In the present study, coupled ETFM+VOF approach is adopted. The implemented model does not require as fine grids as demanded by the volume of fluid (VOF) approach alone and is expected to provide numerical results in less time compared to the conventional approaches. A wetting and drying model is coupled with Eulerian Thin-Film model (ETFM) to analyze the wetting and drying behavior inside the bearing chamber, this combined model is referred as the enhanced ETFM throughout this paper. In the enhanced model, an additional source term is included to account for the contact angle effect. In order to define boundary conditions for contact line model used in the present study, dynamic contact angle approach is used. The characteristic of dynamic contact angle is, it keeps on changing with the flow. In the numerical model, this behavior is simulated by sampling contact angle randomly from a Gaussian distribution and extracting information from static/mean contact angle and standard deviation [31]. Before predicting the wetting and drying behavior in the bearing chamber, enhanced ETFM model is first validated against experimental results of Meredith et al. [26] for flow down an inclined flat plate. To cross-verify the applicability of enhanced ETFM for bearing chamber, the numerical results are also compared with the experimental results available in the open literature for a simplified bearing chamber. The shaft speed, $\mathrm{n}=5,000 \mathrm{RPM}$ is selected so that the lubricant flow falls in the first flow regime where dry zones are expected to appear more frequently as compared to the second flow regime. The effect of lubricant contact angle is also investigated by varying contact angle in the range of $10^{\circ}$ to $45^{\circ}$.

\section{PROBLEM DESCRIPTION}

In the present work, a wetting and drying model is coupled with Eulerian Thin-Film model (ETFM) to analyze the wetting and drying behavior inside the bearing chamber, this combined model is referred as the enhanced ETFM throughout this paper. In the enhanced model, an additional source term is included to account for the contact angle effect. The finite volume based solver ANSYS-Fluent is used for this work. The computational domain considered in the present study is shown in Fig. 2 which reproduces the main bearing chamber of the test rig of Kurz et al. [32]. All the dimensions marked in the figure are in $\mathrm{mm}$. The diameter $\left(\mathrm{D}_{\mathrm{c}}\right)$ and axial-length $\left(\mathrm{L}_{\mathrm{a}}\right)$ of the bearing chamber are $222 \mathrm{~mm}$ and $66 \mathrm{~mm}$, respectively. A concentric shaft of diameter, $\mathrm{D}_{\mathrm{s}}=128 \mathrm{~mm}$ rotates through the whole length of the chamber. 
The lubricating oil enters into the chamber from the roller bearings which are mounted on the one end of the shaft. In the present computational analysis, rather than modelling full bearing geometry, oil inlet was modelled as a plain surface based on the recommendation of Krug [33]. Moreover, the oil emerges with a swirl angle $\gamma=50^{\circ}$ from the plain surface based on the guidelines of Bristot et al. [18] to model the behavior of oil shading from the bearing. Bearing chambers are pressurized to avoid the oil leakage. Labyrinth air seal are mounted on the other end of the shaft. In the computational model, labyrinth air seal are modeled as a plain surface analogous to bearing surface. The width and height of this surface is $3 \mathrm{~mm}$ and $0.7 \mathrm{~mm}$, respectively. Circular vent and scavenge pipes of diameter 10 $\mathrm{mm}$ are located at the top and the bottom of the chamber along the axial centerline. In order to model scavenge pump, an approach proposed by Robinson et al.[34] was adopted.
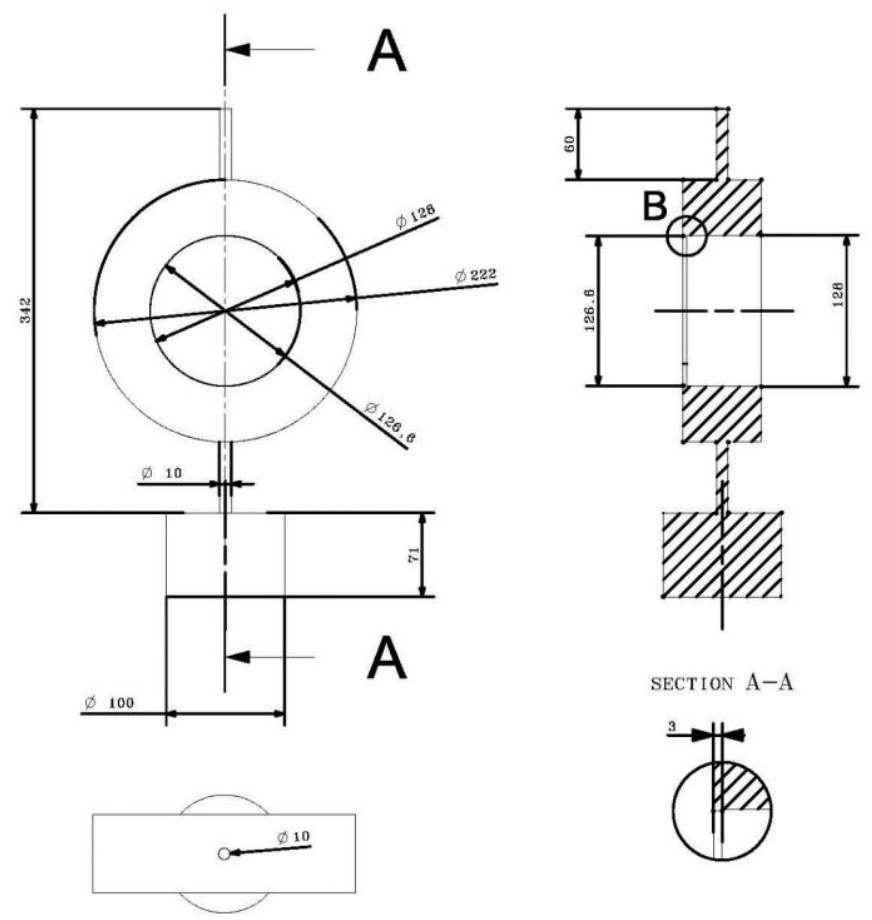

Fig. 2: Schematic diagram of computational domain.

\section{MATHEMATICAL MODEL \\ Thin Film Model}

The assumptions in the thin film model are: advection is considered in the surface tangential direction and diffusion of mass/momentum/energy is considered in the normal direction to the surface. These assumptions are valid for very thin liquid film $(\approx 1 \mathrm{~mm})$ over solid substrate as described by Meredith et al. [26], Wang et al. [24]. The depth-averaged continuity and momentum equations for thin film model with the above assumption are given in Equations (1) and (2).

$$
\frac{\partial \rho \delta}{\partial t}+\nabla_{S^{*}}[\rho \delta U]=S_{\rho \delta}
$$

$\frac{\partial \rho \delta U}{\partial t}+\nabla_{S^{*}}[\rho \delta U U]=-\delta \nabla_{s} p+S_{\rho \delta U}$

where $\rho$ - liquid density, $\delta$ - film thickness, $U$ - film velocity, $\mathrm{S} \rho \delta$ - mass source term per unit wall area due to impingement, splashing, evaporation, absorption. For the present problem, $\mathrm{S} \rho \delta$ $=0$. First term on the right hand side in momentum equation (2) represents source term based on pressure which comprises of pressure due to capillary $\left(p_{\sigma}\right)$, hydrostatic pressure head $\left(p_{\delta}\right)$, local gas phase pressure $\left(p_{g}\right)$ which is given in Equation (3).

$$
p=p_{\sigma}+p_{\delta}+p_{g}
$$

The second term on right side of momentum equation (2) is stress based source terms which comprises of viscous shear stresses $\left(\tau_{\mathrm{g}}+\tau_{\mathrm{w}}\right)$, gravity body force $\left(\rho_{\mathrm{t}} \delta\right)$ and contact angle force $\left(\tau_{\theta}\right)$, given in Equation (4)

$$
S_{\rho \delta U}=\left(\tau_{g}+\tau_{w}\right)+\rho g_{\mathrm{t}} \delta+\tau_{\theta}
$$

Partial wetting behavior can only be captured by treating contact line. Surface tangential force along the contact line limits the film from spreading. This term plays an important role only in the case of partially wetting fluids. The contact angle force which depends on surface tension of solid-liquid, liquid-gas and solidgas interface can be expressed by equation (5) invoking Young's law [35].

$$
\tau_{\theta}=\beta \frac{\sigma\left(1-\cos \theta_{\mathrm{E}}\right)}{\Delta_{c l}} n_{c l}
$$

where, $\sigma$ - surface tension of liquid-gas interface, $\theta_{E}$ - contact angle, $\Delta_{c l}$ - width of computational cell in the direction normal to contact line represented by $\mathrm{n}_{\mathrm{cl}}, \beta$ - empirical parameter to account the discrepency in theortical model and experimental observations.

In the case of enhanced ETFM contact angle force is included in the stress term to account the wetting and drying behavior accurately.

\section{Turbulence Modelling and Free Surface Tracking}

Flow field inside the bearing chamber is three dimensional, incompressible and turbulent [36,37]. In the present study, Reynolds Averaged Navier-Stokes (RANS) equations are solved. RANS equations are time-averaged form of Navier-Stokes equation which accounts the effect of turbulence without modelling every single oscillation explicitly in the flow field. Momentum equation after Reynolds averaging takes the form given in equation (6) for incompressible flow

$$
\rho \frac{\partial U_{i}}{\partial t}+\rho U_{j} \frac{\partial U_{i}}{\partial x_{j}}=-\frac{\partial p}{\partial x_{i}}+\frac{\partial}{\partial x_{j}}\left(2 \mu S_{j i}-\rho \overline{u_{\imath}^{\prime} u_{\jmath}^{\prime}}\right)
$$

where $S_{j i}$ is mean strain rate tensor and $-\rho \overline{u_{\imath}^{\prime} u_{\jmath}^{\prime}}=\tau_{j i}=\tau_{i j}$ are Reynolds stresses. Because of the Reynolds stresses analytical closure of equation (6) is not possible. The Boussinesq 
hypothesis, given in Equation (7) is used to calculate Reynolds stresses.

$$
-\rho \overline{u_{\imath}^{\prime} u_{\jmath}^{\prime}}=\mu_{t}\left(\frac{\partial U_{i}}{\partial x_{j}}+\frac{\partial U_{j}}{\partial x_{i}}\right)-\frac{2}{3} \rho k \delta_{i j}
$$

where $u^{\prime}$ - fluctuating component of velocity, $\mu_{t}-$ turbulent viscosity and $\mathrm{k}$ - turbulent kinetic energy.

Two-equation turbulence model, Shear Stress Transport (SST) $\mathrm{k}-\omega$ is used to achieve turbulence closure. SST k- $\omega$ turbulence model is preferred over standard $k-\omega$ as the requirement of wall $\mathrm{y}^{+} \approx 2$ for standard $\mathrm{k}-\omega$ to explicitly resolve viscous sublayer [38]. The merit of using ETFM approach will be lost if the grids are refined close to the chamber wall to meet wall $\mathrm{y}^{+}$criterion. Turbulent quantities such as $\mathrm{k}$ and $\omega$ are used to calculate velocity scale and length scale which are $\sqrt{k}$ and $\frac{\sqrt{k}}{\omega}$ respectively for the selected turbulence model.

In the present study, VOF method is used to resolve core air and oil flow. ETFM is used in the region where grids are not refined enough to resolve oil film i.e. close to the chamber walls. In the VOF approach, all the fluids filling a cell are treated as a mixture. All the constituent phases are considered at the same speed in a given cell. In the case of stratified flow when participating fluids has significant density difference this situation leads to a non-physical turbulent momentum transfer between the phases. The ratio of densities of lubricating oil and air for bearing chamber application falls in the range of 500 to 800 and hence for these applications inaccurate turbulent momentum transfer is expected without an adequate treatment. Numerical studies of Krug et al. [17] and Bristot et al. [18] on bearing chamber using VOF approach reported the issue of nonphysical turbulent momentum transfer. In order to resolve the issue of turbulent momentum transfer Egorov [39] implemented a source term in $\omega$ equation of $k-\omega$ model to introduce solid wall like damping of turbulence at the interface of both the phases. This source term accounts the effect of fluid viscosity and density, given by equation (8)

$$
\text { A. } \Delta y \beta_{t} \rho_{i}\left(B \cdot \frac{6 \mu_{i}}{\beta_{t} \rho_{i} \Delta n^{2}}\right)^{2}
$$

where, $\mathrm{A}$ is interface area density, subscript $\mathrm{i}$ presents ith phase, $\beta_{t}$ the closure coefficient of the destruction term, $\rho$ is density, $\mathrm{B}$ is a scaling coefficient known as turbulence damping factor, $\mu$ is viscosity and $\Delta n$ is the near-wall cell height.

The source term as given in equation (8) involves a parameter that is dependent on the grid resolution near the wall and hence computational grids are expected to influence the results. Another important parameter that influences the interface momentum transfer is turbulence damping parameter (B). Egorov [39] recommended a value of 10 for turbulence damping factor (B) for grids having $\mathrm{y}^{+}=1$ at the interface and a higher value for the coarser mesh. Tkaczyk [40] and Adeniyi et al. [41] utilized this approach for the application of baring chambers. Tkaczyk [40] conducted numerical studies to investigate the influence of $B$ on stratified flows in a channel. Based on this study, Tkaczyk [40] recommended a value of 100 for turbulence damping factor for relatively coarser mesh. In the present study, this value of turbulence damping factor is adopted.

\section{OPERATING CONDITIONS AND FLUID PROPERTIES}

Numerical simulations are carried out for the operating conditions used by Kurz et al. [32] in their experimental investigations. Air and oil are considered as working fluids. The material properties corresponding to the operating conditions of test cases are summarized in Table-1.

Table-1 Operating conditions and material properties taken from Kurz et al. [32].

\begin{tabular}{lll}
\hline $\begin{array}{l}\text { Operating Conditions } \\
\text { Air mass flow rate }\end{array}$ & 10 & $\mathrm{~g} / \mathrm{s}$ \\
Oil flow rate & 100 & $1 / \mathrm{hr}$ \\
Inlet swirl angle & $50^{\circ}$ & - \\
Chamber pressure & 2.7 & $\mathrm{bar}$ \\
Air temperature & 373 & $\mathrm{~K}$ \\
Pump scavenge ratio & 4 & - \\
Material Properties & & \\
Air density & 2.52 & $\mathrm{~kg} / \mathrm{m}^{3}$ \\
Air viscosity & $2.21 \times 10^{-5}$ & $\mathrm{~kg} / \mathrm{ms}^{3}$ \\
Oil density & 929.5 & $\mathrm{~kg} / \mathrm{m}^{3}$ \\
Oil viscosity & $4.83 \times 10^{-3}$ & $\mathrm{~kg} / \mathrm{ms}$ \\
Oil-air surface tension & $2.45 \times 10^{-2}$ & $\mathrm{~N} / \mathrm{m}$ \\
\hline
\end{tabular}

\section{BOUNDARY CONDITIONS AND MESH}

The boundary conditions imposed on the computational domain are depicted in Fig. 3. Mass flow inlet boundary condition with a swirl angle, $\gamma=50^{\circ}$ is specified at the inlet of air and oil surfaces based on the guidelines of Bristot et al. [18]. Rotating wall boundary condition is imposed on the shaft. The direction of rotation is clockwise when seen from the bearing side. At the outlet of the vent, pressure outlet boundary conditions is used. In order to model the sump-pump, a negative velocity boundary condition is imposed at the sump outlet. The value of velocity magnitude is set on the basis of scavenging ratio. Non-slip wall boundary condition is imposed on all the other surfaces. ETFM model requires the additional information on the walls. Eulerian wall film conditions are specified at the chamber and shaft walls accounting flow-momentum coupling.

In the case of Enhanced ETFM model, additional inputs are required for lubricant to wall contact angle, standard deviation of contact angle and model empirical parameter $(\beta)$. Lubricating oil to wall contact angle influence the spreading of oil onto the solid walls. The lubricating oil contact angle was not determined in the experimental study of Kurz et al. [32] which is a reference case for validation of present numerical simulation. Kuznetsov and Martynov [42] showed that the oil contact angle decrease with incraese in operating temperature. Hence, in the present study, contact angles were varied from $10^{\circ}$ to $45^{\circ}$ to cover a wide operating range. All the studies are conducted for empirical parameter, $\beta=1$ and $5 \%$ standard deviation in the contact angle. 
Non-uniform structured grids are generated using ICEM/CFD, a pre-processor to ANSYS/FLUENT. Grids with 1,817,260 cells are used in the present study.

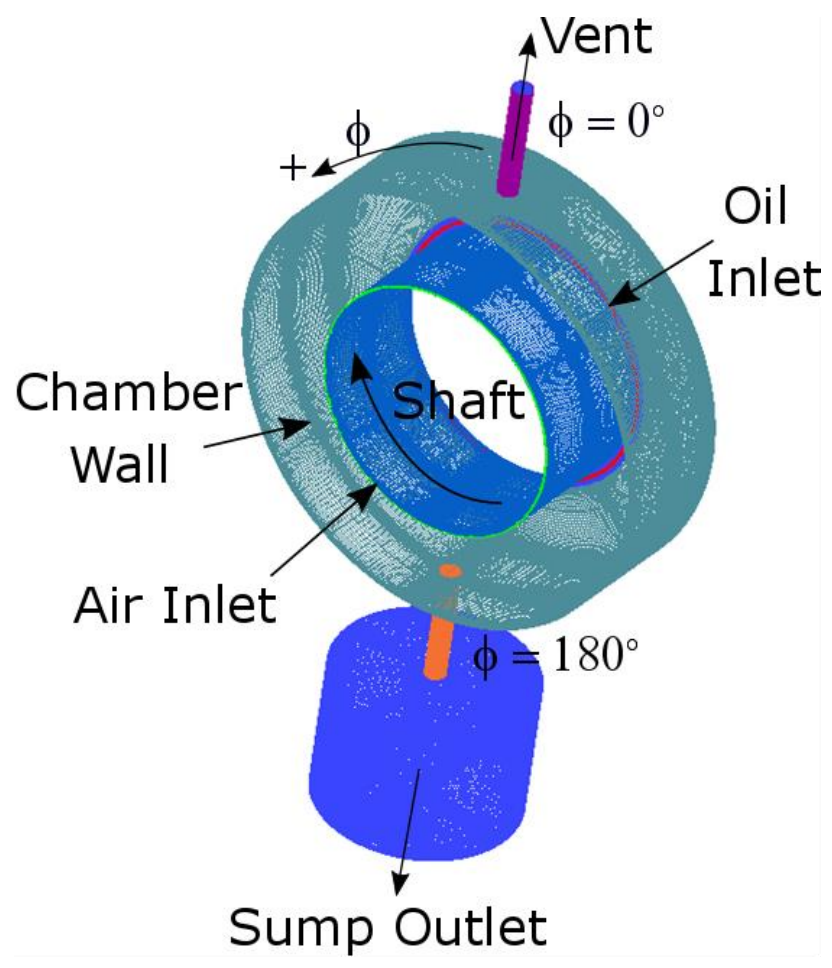

Fig. 3 A typical mesh and boundary conditions imposed on the computation domain.

\section{NUMERICAL METHODS AND SOLUTION PROCEDURE}

Coupled level set and Volume-of-Fluid (VOF) methods are used for surface capturing. Eulerian Thin Film Model (ETFM) is used to resolve oil film in the regions close to the chamber wall. Compressive interface capturing scheme is used based on the recommendation of Bristot [43] which allowed the usage of implicit scheme for temporal discretization. The second-order upwind interpolation scheme is used for spatial discretization of the governing equations. Coupled algorithm is used for pressurevelocity coupling.

\section{VALIDATION AND DISCUSSION Study on Flat Plate}

In order to validate the enhanced ETFM for film flows with partial wetting and drying effects, the experimental data from Meredith et al. [26] was adopted for simulations and validations of the model. In these experiments, Infrared camera was used to obtain qualitative images of the liquid film distribution over an inclined flat plate. In addition, the wet area fractions were evaluated from processing of the obtained images, to provide quantitative data about the film distribution. No measurement of film thickness was available from these experiments. The wet area fraction is calculated as the fraction of the wet area to the total area of the plate surface.

The experimental apparatus consists of a flat plate with $0.61 \mathrm{~m}$ width and $1.22 \mathrm{~m}$ long. The inclination of the plate was varied between $5^{\circ}$ and $90^{\circ}$. The working fluid was water at $43^{\circ} \mathrm{C}$ which was discharged from a perforated tube positioned laterally at the top. After that, in order to establish a smooth film flow, the water was forced to flow through a diffusive medium, and the film falls down under the effect of gravity. Different experiments were conducted with varying the flow rate to investigate the distribution of the film and the effect on the wet area fraction.

Numerical simulations were conducted with Ansys Fluent 19.2 with activation of the contact angle force. A threedimensional structured mesh of about 0.7 million cells was used. The mesh is uniform in the streamwise and spanwise directions, but it is stretched towards the wall in the normal direction. A typical mesh used in this study is shown in Fig. 4. A mass source term for the thin film model is implemented in a User Defined Function (UDF) to account for the inlet mass flow rate. The contact angle is $75^{\circ}$ and the standard deviation was assumed to be $10 \%$. Also, a default value of model empirical parameter $\beta$ is assumed to be 1.0 .

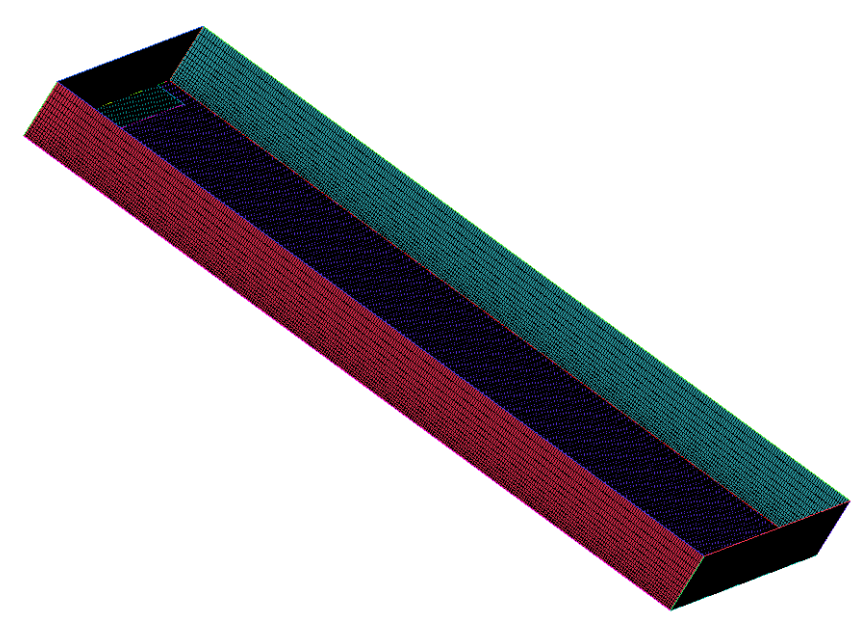

Fig. 4 computational mesh showing the inlet source of the thin film flow.

Gravity, surface shear force, pressure gradient, spreading term and surface tension force were considered in the simulations. All physical properties of water were provided at a temperature $43^{\circ} \mathrm{C}$. Second order upwind scheme was used to discretize convective terms in the momentum equations with a time step of $2 \mathrm{~ms}$. A subdivision of 10 time steps for each time step of the air flow is used for solution of the thin film equations which allows for Courant number less than 1 adopting an explicit solver for the thin film equations. The total film mass is monitored during the calculations and the simulation is concluded when it stabilizes at a constant value.

Figure 5 shows the film thickness distribution for an inclination angle of $5^{\circ}$ and mass flow rate of $\Gamma=31 \mathrm{~g} / \mathrm{m} / \mathrm{s}$ along with experimental data of Meredith et al. [26] for qualitative comparisons. At this low flow rate, the film does not wet the 
whole surface of the plate and flow with rivulets is observed which can be reproduced fairly well by numerical simulations. It is expected that the exact shape of the rivulets produced from experiments cannot be reproduced in numerical simulation due to the random nature of this phenomenon. However, it is interesting that the simplified ETFM with enhanced features for wetting and drying is capable to predict this complicated behavior. Figure 5 (c) reveals that the rivulet formation is not captured with the ETFM model without considering contact line force term. This indicates the significances of the contact line force term in predicting partial wetting behavior. Moreover, calculations of wet area fraction gives a value of 0.17 compared to an experimental value of 0.1 .
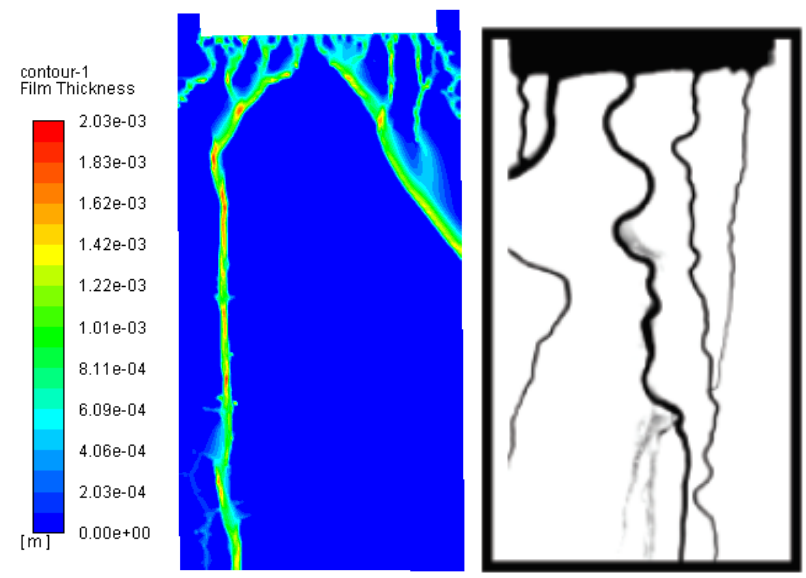

(a)

(b)
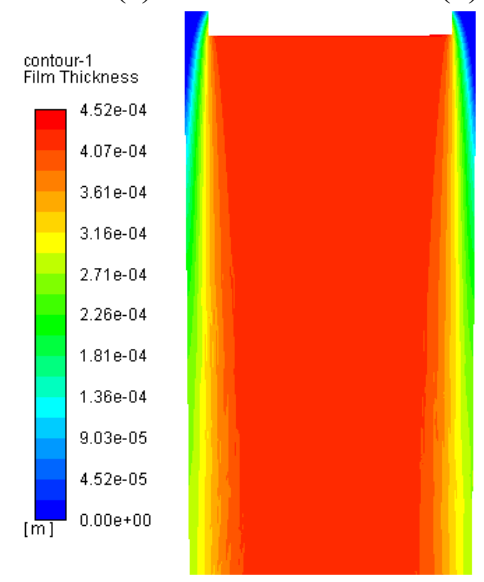

(c)

Fig. 5 Film thickness distribution for inclination angle $5^{\circ}$ and flow rate $=31 \mathrm{~g} / \mathrm{m} / \mathrm{s}$ (a) numerical result obtained from enhanced ETFM (b) experimental results of Meredith et al. [26] (courtesy of WIT Press) (c) numerical result obtained from ETFM i.e. without considering contact line force term.

With increase of inlet mass flow rate to $505 \mathrm{~g} / \mathrm{m} / \mathrm{s}$ for a plate with inclination angle of $90^{\circ}$, continuous film flow was reported in the experimental study of Meredith et al. [26]. This effect is reproduced in the numerical simulations as can be seen in Fig. 6.
Moreover, the film width downstream the plate predicted by the numerical study is larger than that reported in the experimental work of Meredith et al. [26]. Nevertheless, a decrease of the film width is predicted with humps in the film thickness close to the boundaries as results of the effect of the contact angle force along the contact line as can be seen in Fig. 6 (a). On the contrary of this, liquid film uniformly covering the plate is witnessed when contact angle forces were neglected as shown in Fig. 6 (c).

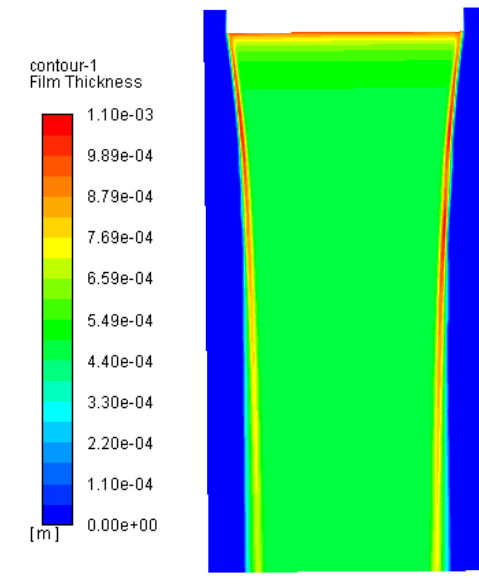

(a)

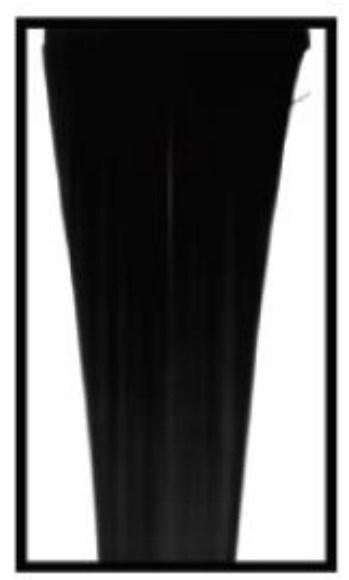

(b)

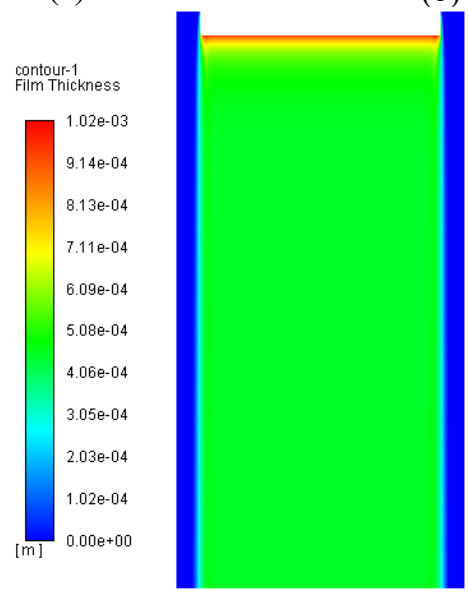

(c)

Fig. 6 Film thickness distribution for inclination angle $90^{\circ}$ and flow rate $=505 \mathrm{~g} / \mathrm{m} / \mathrm{s}$ (a) numerical result obtained from enhanced ETFM (b) experimental results of Meredith et al. [26] (courtesy of WIT Press) (c) numerical result obtained from ETFM i.e. without considering contact line force term.

\section{Study on Bearing Chamber}

In most of the experimental investigations on bearing chamber, film thickness on the periphery of the chamber wall is reported. Wetting and drying behavior of the chamber wall is reported neither quantitatively nor qualitatively. Hence, film thickness obtained from the numerical studies is compared with the experimental measurement of Kurz et al. [32]. In the study of Kurz et al. [32] film thickness was measured at eight locations using capacitive sensors of $10 \mathrm{~mm}$ diameter along the periphery 
of the bearing chamber. In the present numerical study, nine computational probes were placed in an equivalent probe area to calculate a sensor area-averaged film thickness. The angular location of measurement points is shown in Fig. 7.

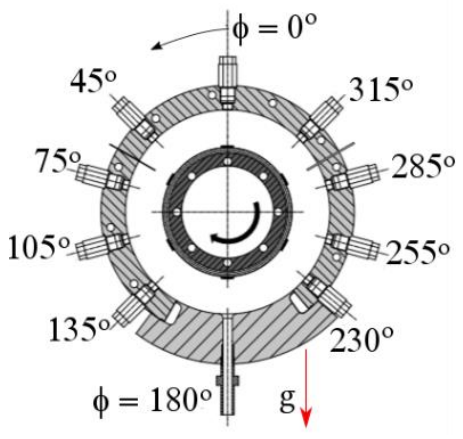

(a)

(b)

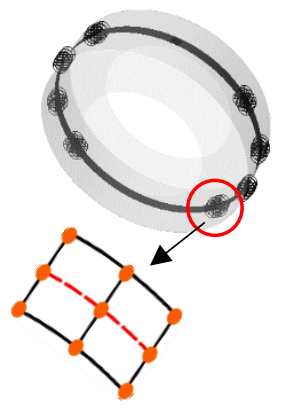

Fig. 7 (a) Angular locations of the sensors for film-thickness measurement in experimental study of Kurz et al. [32] (b) nine point probe scheme for numerical model at sensor location $230^{\circ}$.

A comparison of film-thickness obtained from ETFM at higher shaft speed $(15,000)$ is shown in Fig. 8. The experimental results of Kurz et al. [32] showed that at 15,000 RPM, a uniform and rotating film is observed at the chamber wall which covers the entire chamber walls. Hence, enhanced thin film model was not used to predict film thickness at higher shaft speed. It can be observed from Fig. 8 that film-thickness predicted by ETFM is following the trends observed in the experimental study. The present numerical results are in better agreement with the experimental results as compared to the numerical results of Bristot et al. [18] obtained from VOF approach.

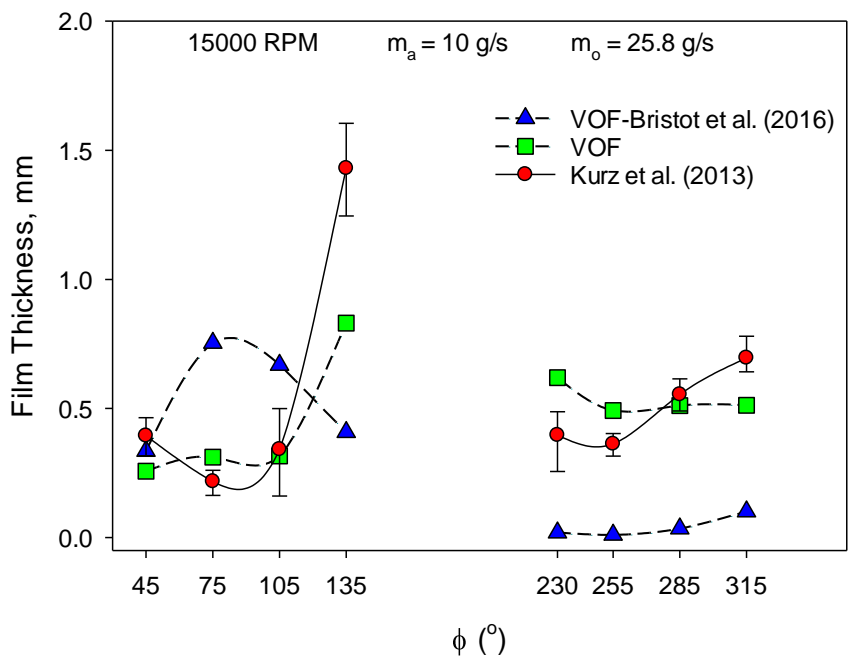

Fig. 8 Comparison of predicted film thickness with the experimental measurement of Kurz et al. [32] and numerical results of Bristot et al. [18].

Moreover, it was observed at lower shaft speed $\approx 5,000 \mathrm{rpm}$, ETFM only approach used in this study, was not sufficient to predict film thickness distribution over the chamber walls.
Hence, a coupled ETFM with VOF model is employed to estimate film thickness distribution over the chamber walls. A comparison of the film thickness obtained from the present numerical study using coupled VOF+ ETFM and Coupled VOF+ enhanced ETFM is shown in Fig. 9 along with a previous numerical study by Krug et al. [17]. The numerical results are obtained at shaft speed of 5,000 rpm, air-flow rate of $10 \mathrm{~g} / \mathrm{s}$ and oil flow rate of $25.8 \mathrm{~g} / \mathrm{s}$. In the case of enhanced ETFM model, oil to surface contact angle (CA) was varied from $10^{\circ}$ to $45^{\circ}$. It can be observed from this figure that the numerical results underpredicts film thickness as compared to the experimental studies. It can also be observed that the film thickness predicted by enhanced ETFM model is lower than that of ETFM model.

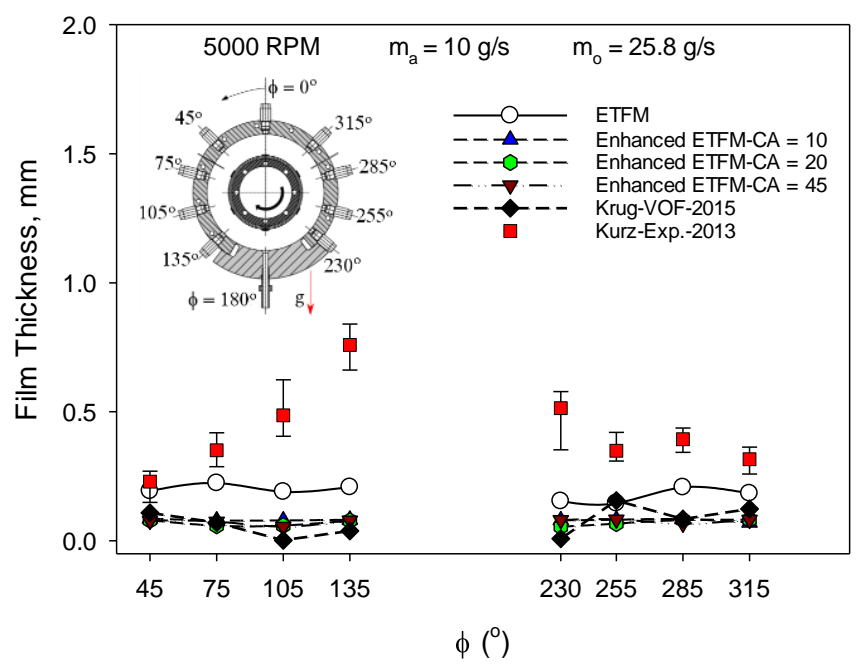

Fig. 9 Comparison of predicted film thickness with the experimental measurement of Kurz et al. [32] and numerical results of Krug et al. [17].

Figure 9 also reveals that the present numerical results obtained from enhanced ETFM are close to the numerical results of Krug et al. [17] obtained from VOF method. Moreover, influence of contact angle is not found to be prominent for the investigated conditions. Although, the present numerical results are under-predicting experimental results yet these results are comparable to the results obtained from VOF which demands comparatively fine grids to resolve thin film on chamber wall

Contours of film thickness on the periphery of chamber wall are shown in Fig. 10 to Fig. 13 for ETFM and enhanced ETFM at the investigated contact angles. A comparative analysis of film thickness contours reveals that the average film thickness in the case of coupled VOF+ETFM is around $0.2 \mathrm{~mm}$ and coupled VOF +enhanced ETFM is $0.05 \mathrm{~mm}$. Eulerian film thickness contours for coupled ETFM case (Fig. 10a) shows almost dryout condition for counter-current location, $150^{\circ}<\phi<180^{\circ}$ and some part of co-current direction, $180^{\circ}<\phi<190^{\circ}$. It is because, in this particular region oil film is resolved by VOF approach. Since, a coupled VOF+ETFM approach is adopted is the present study which transfers film mass from ETFM to VOF if total volume fraction in a cell is $>0.5$. This is confirmed by the contours of iso-surface of constant volume fraction $(\alpha=0.5)$ of 
oil, shown in the offset of Fig. 10 (b). As the contours in Fig. 10 to 13 shows only ETFM contribution in the calculation of film thickness and hence the predicted film thickness is zero in the region $150^{\circ}<\phi<180^{\circ}$.

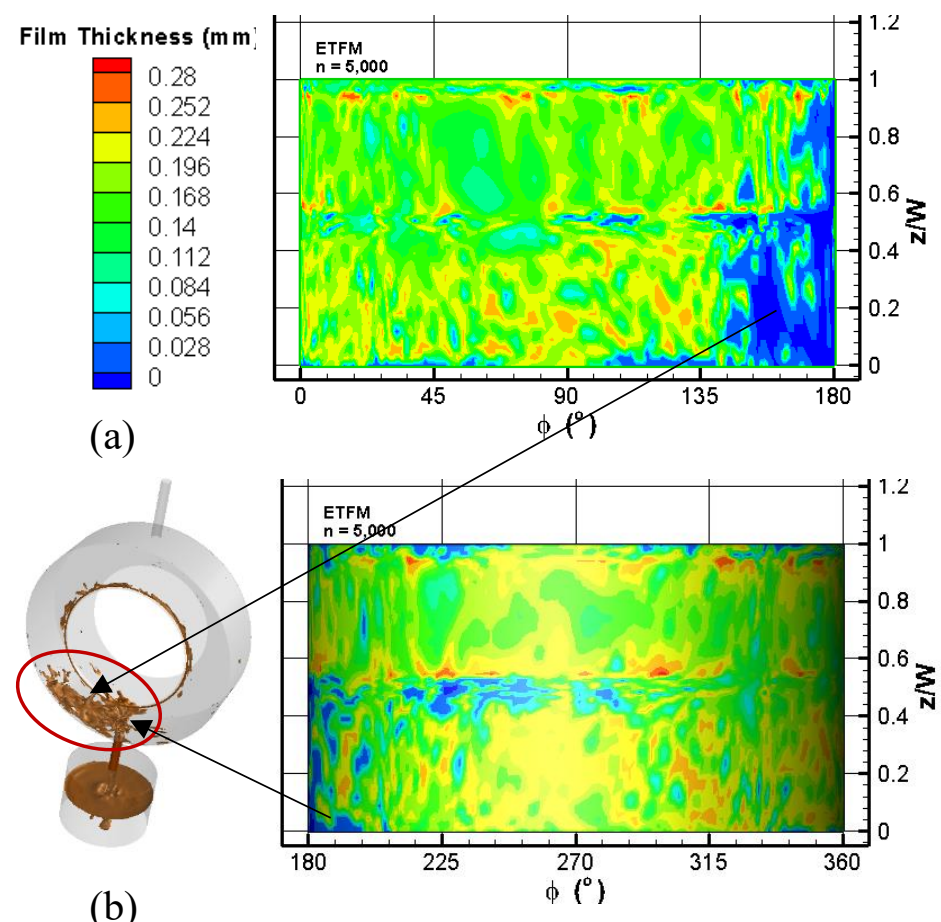

Fig. 10 Contours of Eulerian film thickness over chamber wall for ETFM at shaft speed, $\mathrm{n}=5,000 \mathrm{rpm}, \mathrm{t}=0.25 \mathrm{~s}$.

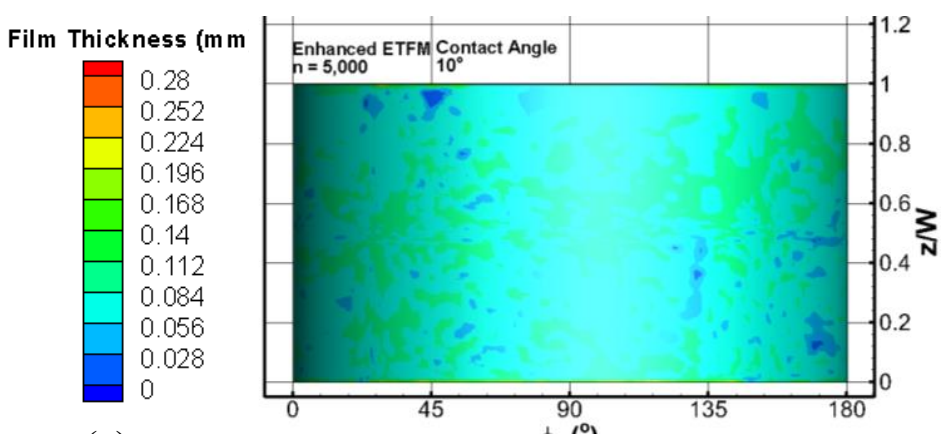

(a)

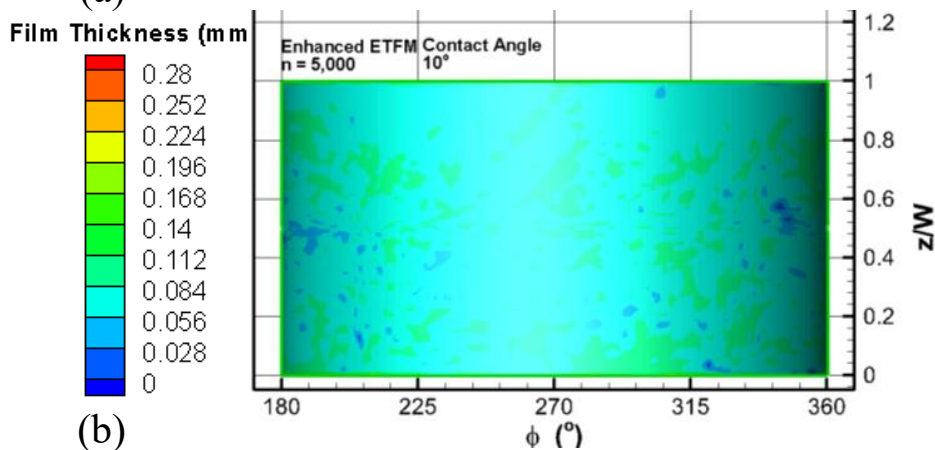

Fig. 11 Contours of Eulerian film thickness over chamber wall for enhanced ETFM at shaft speed, $\mathrm{n}=5,000 \mathrm{rpm}, \mathrm{t}=0.25 \mathrm{~s}$, contact angle $=10^{\circ}$.

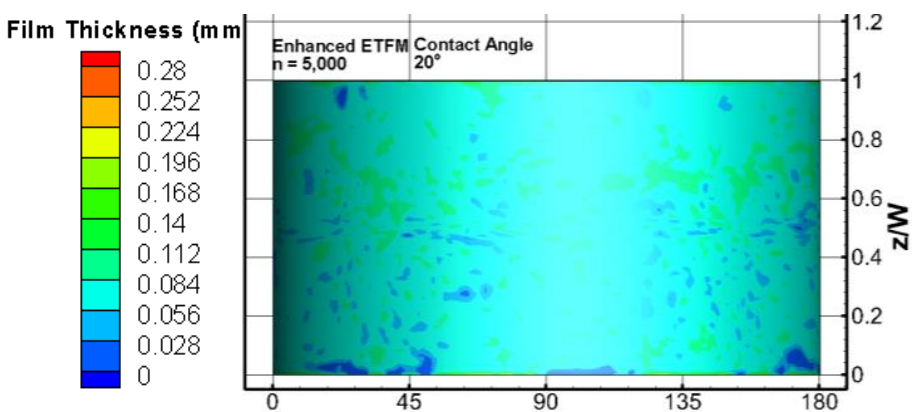

(a)

Film Thickness $(\mathrm{mm}$

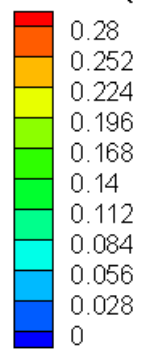

(b)

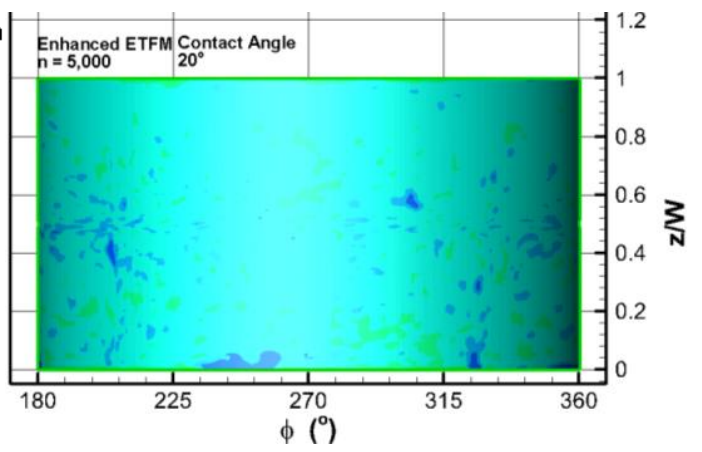

Fig. 12 Contours of Eulerian film thickness over chamber wall for enhanced ETFM at shaft speed, $\mathrm{n}=5,000 \mathrm{rpm}, \mathrm{t}=0.25 \mathrm{~s}$, contact angle $=20^{\circ}$.

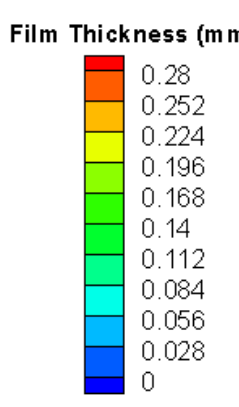

(a)

Film Thickness (m m

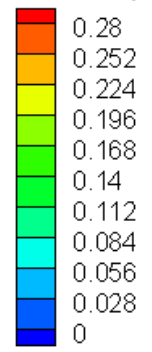

(b)

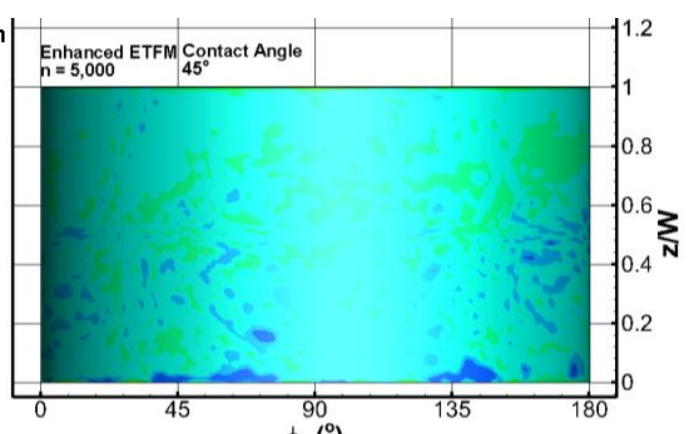

$\phi\left({ }^{\circ}\right)$

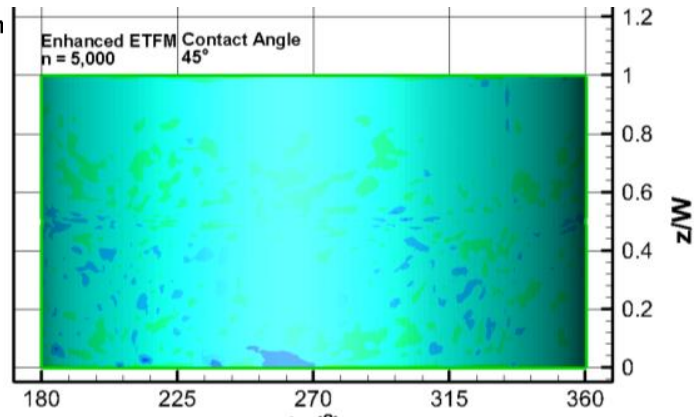

$\phi\left({ }^{\circ}\right)$
Fig. 13 Contours of Eulerian film thickness over chamber wall for enhanced ETFM at shaft speed, $\mathrm{n}=5,000 \mathrm{rpm}, \mathrm{t}=0.25 \mathrm{~s}$, contact angle $=45^{\circ}$. 
On the contrary to the ETFM case, film thickness in enhanced case at all the contact angles is around $50 \mu \mathrm{m}$ with the patches of film thickness $<10 \mu \mathrm{m}$ as can be seen in Fig. 11 to Fig. 13. Because of unavailability of experimental measurement, a comparative analysis is not possible. In addition to that, preliminary studies on the flat plate for gravity driven film shows that empirical parameter, $\beta$ of partial wetting and drying model needs to be adjusted to match the drying and wetting behavior with the experimental results. This sensitivity analysis for the bearing chamber application is not possible for the present scenario due to unavailability of experimental results.

\section{CONCLUSION AND RECOMMENDATIONS}

In the present work, a wetting and drying model is coupled with Eulerian Thin-Film model (ETFM) to analyze the wetting and drying behavior inside the bearing chamber, this combined model is referred as the enhanced ETFM. In the enhanced model, an additional source term is included to account for the contact angle effect. These models were coupled with volume-of-fluid (VOF) such that the core region is resolved by VOF and the region close to the chamber walls is resolved by either ETFM or enhanced ETFM model where a thin film is expected. Numerical studies are conducted for a shaft speed of 5,000 rpm, lubricant and airflow rates of $100 \mathrm{l} / \mathrm{hr}$ and $10 \mathrm{~g} / \mathrm{s}$ respectively, at a scavenging ratio of 4 . In the case of enhanced ETFM model lubricant to surface contact angle was varied from $10^{\circ}$ to $45^{\circ}$. Because of unavailability of experimental data for wetting and drying behavior of bearing chamber, the performance of enhanced ETFM model is evaluated on flat plate geometry.

The numerical results on the flat plate revealed that the enhanced ETFM model is capable to reproduce the wetting and drying behavior. Although, the exact shape of the rivulets produced from experiments cannot be reproduced in numerical simulation due to the random nature of this phenomenon, yet qualitative trends are captured well. It is observed from the numerical study on bearing chamber that the coupled VOF+ETFM approach captured the qualitative trend of oil film formation and distribution over the chamber wall. A lower value of film thickness is predicted from enhanced ETFM approach as compared to ETFM. Moreover, the numerical results of enhanced ETFM model are in good agreement with the VOF results reported in the literature. Both, ETFM and enhanced ETFM model under-predicted experimental results.

The coupling of VOF with ETFM and enhanced ETFM is still in development and further improvement in the modelling approach include a better understanding of the effects of switching criterion from ETFM to VOF or vice versa and local mesh resolution based on the switching criterion is recommended. Preliminary studies on the flat plate for gravity driven film shows that empirical parameter, $\beta$ of partial wetting and drying model needs to be adjusted to match the drying and wetting behavior with the experimental results. A sensitivity analysis to get suitable value of this empirical parameter for aeroengine bearing applications is recommended.

\section{ACKNOWLEDGMENTS}

The research leading to these results has received funding from the Clean Sky 2 Joint Undertaking under the European Union's Horizon 2020 research and innovation programme under grant agreement No 724625.

The calculations were performed using the University of Nottingham High Performance Computing Facility and Athena at HPC Midlands+, which was funded by the EPSRC on grant EP/P020232/1.

\section{REFERENCES}

[1] W. Kurz, K. Dullenkopf, H.-J. Bauer, Influences on the Oil Split between the Offtakes of an Aero-Engine Bearing Chamber, in: Proc. ASME Turbo Expo 2012 GT2012, 2012: pp. 1-9.

[2] C. Eastwick, K. Huebner, B. Azzopardi, K. Simmons, C. Young, R. Morrison, Film Flow Around Bearing Chamber Support Structures, ASME Conf. Proc. 2005 (2005) 1267-1272. doi:10.1115/GT2005-68905.

[3] K. Singh, B. Premachandran, M.R. Ravi, Experimental and numerical studies on film cooling of a corrugated surface, Appl. Therm. Eng. 108 (2016) 312-329. doi:10.1016/j.applthermaleng.2016.07.093.

[4] K. Singh, B. Premachandran, M.R. Ravi, Effect of Thermal Barrier Coating and Gas Radiation on Film Cooling of a Corrugated Surface, J. Heat Transfer. (2018). http://dx.doi.org/10.1115/1.4039761.

[5] W. Kurz, H.-J. Bauer, An Approach for Predicting the Flow Regime in an Aero Engine Bearing Chamber, in: Proc. ASME Turbo Expo 2014 Turbine Tech. Conf. Expo., 2014: pp. 1-8. doi:10.1115/GT2014-26756.

[6] Y. Iso, X. Chen, Flow Transition Behavior of the Wetting Flow Between the Film Flow and Rivulet Flow on an Inclined Wall, J. Fluids Eng. 133 (2011) 091101. doi:10.1115/1.4004765.

[7] R.K. Singh, J.E. Galvin, X. Sun, Three-dimensional simulation of rivulet and fi $\mathrm{lm}$ fl ows over an inclined plate: Effects of solvent properties and contact angle, Chem. Eng. Sci. 142 (2016) 244-257. doi:10.1016/j.ces.2015.11.029.

[8] R.K. Singh, J.E. Galvin, G.A. Whyatt, X. Sun, Breakup of a liquid rivulet falling over an inclined plate: Identification of a critical Weber number, Phys. Fluids. 29 (2017). doi:10.1063/1.4981920.

[9] H. Bonart, A. Marek, J.U. Repke, Experimental characterization of stable liquid rivulets on inclined surfaces: Influence of surface tension, viscosity and inclination angle on the interfacial area, Chem. Eng. Res. Des. $125 \quad$ (2017) 226-232. doi:10.1016/j.cherd.2017.07.022.

[10] F. Veron, W.K. Melville, Experiments on the stability and transition of wind-driven water surfaces, J. Fluid Mech. $446 \quad$ (2001) 25-65. doi:10.1017/S0022112001005638.

[11] J.R. Marati, M. Budakli, T. Gambaryan-Roisman, P. Stephan, Heat Transfer in Shear-Driven Thin Liquid 
Film Flows, Comput. Therm. Sci. 5 (2013) 303-315. doi:10.1615/ComputThermalScien.2013006073.

[12] H. Lan, M. Friedrich, B.F. Armaly, J.A. Drallmeier, Simulation and measurement of 3D shear-driven thin liquid film flow in a duct, Int. J. Heat Fluid Flow. 29 (2008) 449-459. doi:10.1016/j.jheatfluidflow.2007.12.003.

[13] M. Leng, S. Chang, H. Wu, Experimental investigation of shear-driven water film flows on horizontal metal plate, Exp. Therm. Fluid Sci. 94 (2018) 134-147. doi:10.1016/j.expthermflusci.2018.02.004.

[14] M. Leng, S. Chang, Y. Lian, H. Wu, Experimental Study of Water Film Dynamics Under Wind Shear and Gravity, $\begin{array}{lllll}\text { AIAA } & \text { J. } & 56 & \text { (2018) } & 1-9 .\end{array}$ doi:10.1002/14651858.CD006573.pub3.

[15] C.W. Hirt, B.D. Nichols, Volume of fluid (VOF) method for the dynamics of free boundaries, J. Comput. Phys. 39 (1981) 201-225. doi:https://doi.org/10.1016/00219991(81)90145-5.

[16] P. Tkaczyk, H.P. Morvan, Methodology for Modelling Two-Phase Flow in Bearing Chambers using CFD ( Volume of Fluid ) - SILOET, 2012.

[17] M.B. Krug, C. Höfler, H. Bauer, W. Kurz, Evaluation of the Volume-of-Fluid Method for the Numerical Modelling of an Aero Engine Bearing Chamber, in: ISABE, 2015: pp. 21248-1-10.

[18] A. Bristot, H.P. Morvan, K.A. Simmons, Evaluation of a Volume of Fluid CFD Methodology for the Oil Film Thickness Estimation in an Aero-Engine Bearing Chamber, in: Proc. ASME Turbo Expo 2016 Turbomach. Tech. Conf. Expo., 2016: pp. 1-11.

[19] B. Kakimpa, H.P. Morvan, S. Hibberd, The numerical simulation of multi-scale oil films using coupled VOF and Eulerian thin-film models, in: Proc. ASME Turbo Expo 2016 Turbine Tech. Conf. Expo. GT2016, Montr. Canada, 2016: pp. 1-9.

[20] J. Ashmore, A.E. Hosoi, H.A. Stone, The effect of surface tension on rimming flows in a partially filled rotating cylinder, J. Fluid Mech. 479 (2003) 65-98. doi:10.1017/S0022112002003312.

[21] E.D. Kay, S. Hibberd, H. Power, A depth-averaged model for non-isothermal thin-film rimming flow, Int. J. Heat Mass Transf. 70 (2014) 1003-1015. doi:10.1016/j.ijheatmasstransfer.2013.11.040.

[22] B. Kakimpa, H. Morvan, S. Hibberd, The DepthAveraged Numerical Simulation of Laminar Thin-Film Flows With Capillary Waves, J. Eng. Gas Turbines Power. 138 (2016) 112501. doi:10.1115/1.4033471.

[23] B. Kakimpa, H.P. Morvan, S. Hibberd, Solution Strategies for Thin Film Rimming Flow Modelling, in: Proc. ASME Turbo Expo 2015 Turbine Tech. Conf. Expo. GT2015, 2015: pp. GT2015-43503-1-9.

[24] C. Wang, H.P. Morvan, S. Hibberd, K. a. Cliffe, Thin Film Modelling for Aero-Engine Bearing Chambers, Vol. 1 Aircr. Engine; Ceram. Coal, Biomass Altern. Fuels; Wind Turbine Technol. (2011) 277-286.
doi:10.1115/GT2011-46259.

[25] M. Martin, T. Defraeye, D. Derome, J. Carmeliet, A film flow model for analysing gravity-driven, thin wavy fluid films, Int. J. Multiph. Flow. 73 (2015) 207-216. doi:10.1016/j.ijmultiphaseflow.2015.03.010.

[26] K. V. Meredith, A.Heather, J. de Vries, Y. Xin, A numerical model for partially-wetted flow of thin liquid film, WIT Trans. Eng. Sci. 70 (2011) 239-250. doi:10.2495/MPF110.

[27] P.G. De Gennes, Wetting: Statics and dynamics, Rev. Mod. Phys. 57 (1985) 827-863. doi:10.1103/RevModPhys.57.827.

[28] C. Huh, L.E. Scriven, Hydrodynamic Model of Steady Movement of a Solid / Liquid / Fluid Contact Line CHUN, J. Colloid Interface Sci. 35 (1971). doi:10.1016/0021-9797(71)90188-3.

[29] S.B.G.O. Brien, L.W. Shwartz, Theory and Modeling of thin film flows, Encycl. Surf. Colloid Sci. (2002) 52835297. doi:10.1081/E-ESCS-120000885.

[30] A. Alizadeh Pahlavan, L. Cueto-Felgueroso, G.H. McKinley, R. Juanes, Thin Films in Partial Wetting: Internal Selection of Contact-Line Dynamics, Phys. Rev. Lett. 115 (2015). doi:10.1103/PhysRevLett.115.034502.

[31] ANSYS Inc., ANSYS Fluent Theory Guide 19.2, 2018.

[32] W. Kurz, K. Dullenkopf, H.-J. Bauer, Capacitive Film Thickness Measurements in a Ventless Aero-Engine Bearing Chamber-Influence of Operating Conditions and Offtake Design, J. Eng. Gas Turbines Power. 135 (2013) 112504. doi:10.1115/1.4025067.

[33] M.B. Krug, Evaluation of the Volume of Fluid Method for the Numerical Modelling of an Aero Engine Bearing Chamber, Dipl.-Ing Thesis, Karlsruhe Institute of Technology, Karlsruhe, Germany, 2012., 2012.

[34] A. Robinson, H. Morvan, C. Eastwick, Computational Investigations Into Draining in an Axisymmetric Vessel,

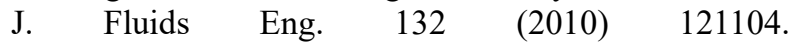
doi:10.1115/1.4003151.

[35] D.E. Hartley, W. Murgatroyd, Criteria for the Break-Up of Thin Liquid Layers Flowing Isothermally Over a Solid Surface, 1964. doi:10.1016/0017-9310(64)900420 .

[36] P. Gorse, K. Willenborg, S. Busam, J. Ebner, K. Dullenkopf, S. Wittig, 3D-LDA Measurements in an Aero-Engine Bearing Chamber, in: Proc. ASME Turbo Expo 2003 Power Land, Sea, Air June 16-19, 2003, Atlanta, Georg. USA, 2003: pp. GT2003-38376-1-9.

[37] A.A. Adeniyi, B. Chandra, K. Simmons, Computational study of a customised shallow-sump aero-engine bearing chamber with inserts to improve oil residence volume, Proc. ASME Turbo Expo. 5B-2017 (2017) 1-10. doi:10.1115/GT2017-64410.

[38] A. Robinson, C. Eastwick, H. Morvan, Further Computational Investigations Into Aero-Engine Bearing Chamber Off-Take Flows, (2010) 209-217. http://dx.doi.org/10.1115/GT2010-22626.

[39] Y. Egorov, Validation of CFD Codes with PTS-Relevant 
Test Cases EVOLECORA-D07, 2004.

[40] P. Tkaczyk, CFD simulation of annular flows through bends, PhD Thesis, The University of Nottingham, 2011.

[41] A.A. Adeniyi, H.P. Morvan, K.A. Simmons, A Transient CFD Simulation of the Flow in a Test Rig of an Aeroengine Bearing Chamber, (2014) V05CT16A030. http://dx.doi.org/10.1115/GT2014-26399.

[42] A.A. Kuznetsov, V.M. Martynov, Contact angle of lubricating oils at elevated temperatures, Chem. Technol. Fuels Oils. 8 (1972) 773-776. doi:10.1007/BF00717076.

[43] A. Bristot, Application of the Volume of Fluid Method with Heat Transfer to a Two- Shaft Aero-Engine Bearing Chamber, University of Nottingham, 2017. 